\title{
On-line Tuning Algorithms Design and Validation for MCU Based on TMS320F28335
}

\author{
Wang Ruoping ${ }^{1, a} \quad$ Yang Yuzhu ${ }^{2, b} \quad$ Gao Haiyu ${ }^{3, c}$ Jiao Xianzheng ${ }^{4, d}$ \\ 1,2 Jiangsu University,Zhenjiang, 212013,Jiangsu Province, P. R. China \\ 3,4 Eontronix.Co.,Ltd Beijing, 100085, P. R. China

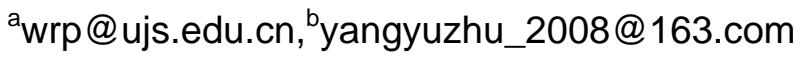

Key words: DSP;embed;power level;algorithm development;rapid prototype

\begin{abstract}
A Model-based rapid algorithms development platform for Motor Control Unit (MCU) is constructed using the latest TI's C2000 series TMS320F28335 which supports floating point arithmetic, integrated with high power IGBT. C code can be automatically generated directly from MATLAB Matlab/Simulink model,compiled and downloaded into the controller to get access to rapid prototype. Taking the Permanent Magnet Synchronous Motor (PMSM) as the test object, experiment results showed that the model created by Matlab/Simulink was efficient and feasible via on-line calibration , which help to reduce the time and cost of algorithm development.
\end{abstract}

\section{Introduction}

Research on drive system for electric cars is one of the three key technologies. Car motor for cars demand simplified structure, reliable operation, small volume, light weight, and high efficiency and high power factor. Worldwide developers on motor controller generally follow the way called V type procedure using Matlab/Simulink simulation and modeling, and code generation to get access to rapid prototype ${ }^{[1]}$. In this paper a new control algorithm are modeled, and a permanent magnet synchronous motor system hardware components was given. Then algorithms modeled in Matlab/Simulink was turned machine-readable code tested and validated using a permanent magnet synchronous motor. Parameters in the form of software such as PID tune values can be calibrated via CAN interface on the upper computer within the process if necessary.

\section{Development Platform System Architecture}

In this study, TI's DSP TMS320F28335 is used as control core. TMS320F28335 support IEEE standard single precision floating-point arithmetic, which save the code execution time and storage space, with high accuracy, low cost, low power consumption, high peripherals integration, large storage of data and process, high A/D conversion rate. So it's more suitable for the embedded industrial application. Controller integrated intelligent power module IGBT as the main circuit switch device. The use of independent or integrated rotary transformer (or incremental encoder) ${ }^{[2]}$ detect rotor position and speed as feedback, and the whole control circuit equipped with hardware protection as well as software algorithm protection.

Three-phase permanent magnet synchronous motor vector controller hardware block diagram are shown in Fig. 1 bellow. The control platform mainly includes the main circuit, detecting circuit and the controller using TMS320F28335 DSP as kernel controller. Main circuit is composed of uncontrolled rectifier module, Intelligent Power Module (IPM) and permanent magnet synchronous motor (PMSM). Detection circuit ${ }^{[3]}$ mainly includes voltage, current signal detection circuit, fault signal detection circuit, speed and position detection circuit, etc. The main functions of the Controller are to realize the functions of the vector algorithm, the realization of PWM drive signal output, input signal processing, the control signal input of the keyboard and display on LCD and online real-time parameter calibration, etc. 


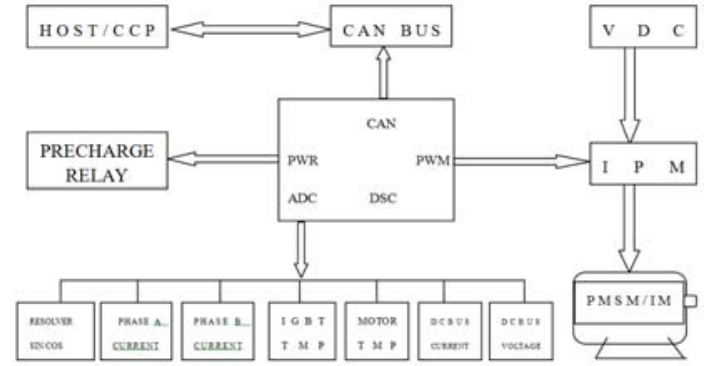

Fig.1 Three-phase permanent magnet synchronous motor vector controller hardware block diagram

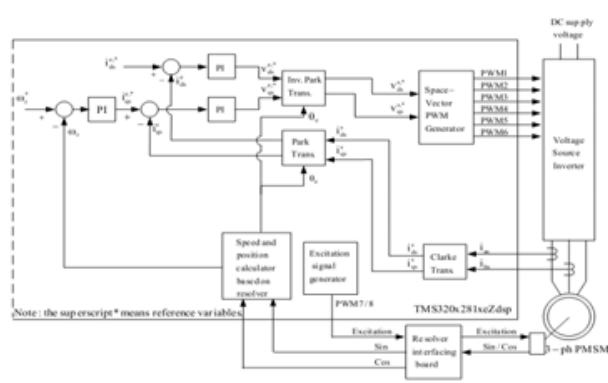

Fig.2. Overall block diagram of field oriented control of PMSM using resolver sensor

\section{Controller Software Design}

\section{Overall Block Diagram}

Permanent magnet synchronous motor rotor field orientation control principle block diagram ${ }^{[4]}$ is shown in Fig. 2. Phase currets $i_{a s}$ and $i_{b s}$, measured with a current sensor, are firstly transformed to the stator current projections in a two co-ordinate non-rotating frame through Clark transformation, then obtain projections in the $(\mathrm{d}, \mathrm{q})$ rotating frame through Park transformation. The $(\mathrm{d}, \mathrm{q})$ projections of the stator phase currents are then compared to their reference values $\mathrm{I}_{q s}^{e^{, *}}$ and $\mathrm{I}_{d s}^{e, *}$ (set to 0) and corrected by mean of PI (or higher intelligent PID) controllers. The outputs of the current controllers are passed through the inverse Park transform and a new stator voltage vector is impressed to the motor using the Space Vector Modulation technique. In order to control the mechanical speed of the motor (speed FOC), an outer loop is driving the reference current $\mathrm{I}_{q s}^{e, *}$ (torque component). The mechanical speed reference is denoted “ $\omega_{r}^{*}$ ” and the mechanical speed “ $\omega_{r}$ ” for notations.

\section{DSP Program Flow}

DSP program ${ }^{[5]}$ is the core of the controller software component, the main function of the controller is realized by DSP program. DSP program(see Fig. 3) is composed of main interrupt program and interruption subroutine. The former realizes DSP initialization, parameter settings etc. interruption subroutine is mainly used to complete voltage, current sampling, the position and speed detection, signal processing , calculation and SVPWM signal generation, etc.
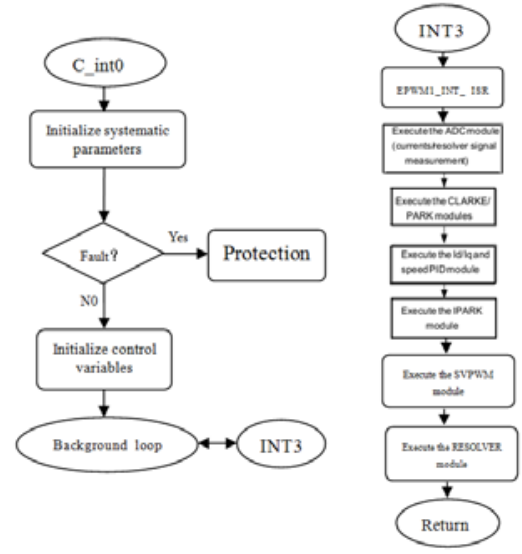

Fig.3. DSP program flow chart

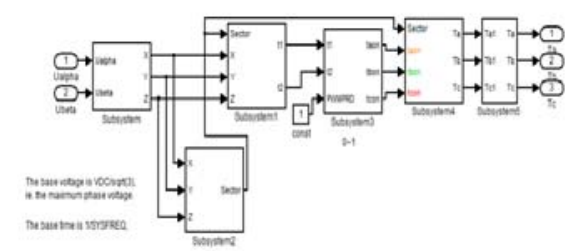

Fig. 4 .SVPWM signal generator models established in Matlab/Simulink

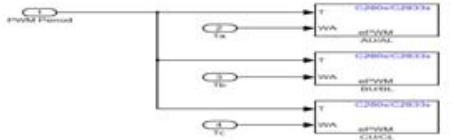

Fig. 5. SVPWM signal generation 
Based on the principle of SVPWM, the simulation models for generating SVPWM $^{[6]}$ waveforms mainly include the sector judgment model, calculation model of operation, time of fundamental vectors, Calculation model of switching time, and generation model of SVPWM waveforms. SVPWM Signal Generator models established in Matlab/Simulink are shown in the Fig. 4.

SVPWM signals are transmitted to ePWM modules in the Simulink DSP sublibrary (see Fig. 5).Software configuration of ePWM modules are shown in Fig. 6 to Fig.8.

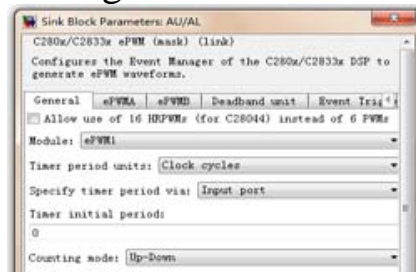

Fig. 6. up-down counter mode

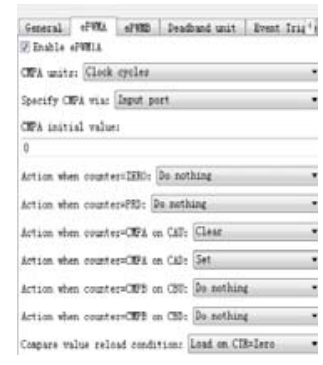

Fig. 7.CMP action mode

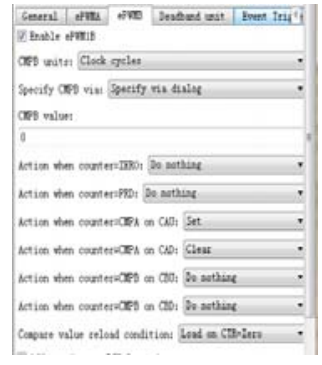

Fig. 8.CMP action mode

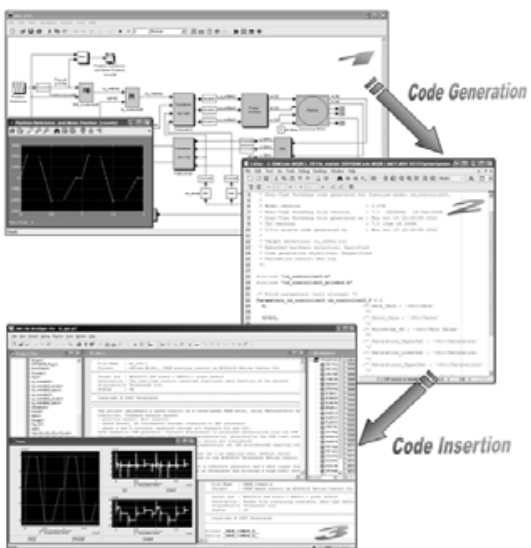

Fig. 9. Process of implementation from system simulation to DSP real-time execution.

\section{Embedded Code Automatic Generation}

TI has offered corresponding development approach for digital motor control applications: start with the model of the complete system, design the control blocks and analyze its expected behavior by simulation, then automatically generate executable code for the target control system and perform the tests on the real system. Fig.9 presents the process of implementation ${ }^{[7,8]}$.

\section{Test and Validation}

In order to validate the controller's control performance designed above, three phase PMSM can be used as the control target. These models can be tested on the actual bench $\mathrm{C}$ Pro digital control real time systems, using the DMC IDE development environment.

Parameters for three-phase permanent magnet synchronous motor (PMSM) to be tested: a pole pairs $p=5$, rated power $P_{n}=10 \mathrm{~kW}$, rated current $I_{n}=300 A$, rated speed $n_{n}=2100 \mathrm{r} / \mathrm{min}$, rated torque $\mathrm{T}_{\mathrm{n}}=200 \mathrm{~N} \cdot \mathrm{m}$.

According to the Incremental System Build ${ }^{[9]}$ algorithm development process TI offered, the software models are tested and verified step by step. Relative variables or parameters measured through corresponding sampling circuit could be transmitted via CAN interface and monitored by host. On line tuning make it convenient to adjust related parameter if necessary.

In open-loop control, the motor rotor position quickly followed reference electrical Angle, the space voltage vector pulse width modulation waveforms (down) correspond with electric angle change. It is visible that control algorithm using SVPWM technique is effective and pleasant. Open loop test has got a smooth speed waveform with preferable precision and response. Fig.10 presents Electrical Angle tracking response and corresponding counting register values TA signal waveform. 




fig. 10. Electrical angle tracking response and counting register values Ta signal waveform

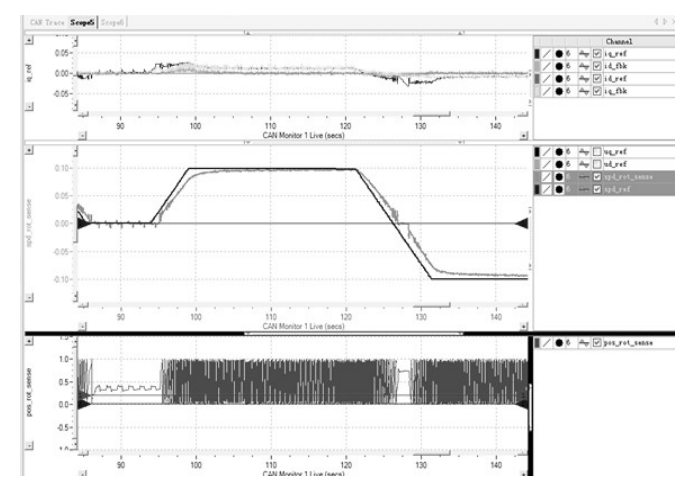

Fig.11 Response of current, speed and electrical angle waveform under 0.1 pu reference

To make the system has high capability of quick response, speed-current double close-loop control method is adopted(see fig.2).Specify the reference speed (step input) 0.1 per unit(pu) measured when the no load motor positive and fig. 11 presents the response of d,q axis current , speed(clockwise and anti-clockwise running )and electrical angle as time goes on. It can be seen that actual speed signal quickly respond the specified value with a nice precision. Control algorithms satisfy the required tracking performance.

\section{Conclusion}

This paper presented a new control algorithm development platform for motor applications based on advanced floating-point DSP. The proposed approach on line tuning to calibrate a motor in the development is introduced to reduce significantly time to write code by hand and makes the engineer to focus on the application functionality and performances, significantly shortening the road from design and laboratory phase to the industrial application level. And most important, more control strategy with kinds of intelligent control system applications will be proposed to improve the application level of whole industry with the development of related technologies.

\section{References}

[1] Liu Jie. Model-Based design and realization of embedded system[M]. The Beijing university of aeronautics \&astronautics press,2010.277-344

[2] Zou Fengxing..Control Device[M]. China Water Power Press ,2011:144-149

[3] TMS320F28335 DATA MENUAL. TEXAS INSTRUMENTS

[4] System Document C2000.TEXAS INSTRUMENTS

[5] Wang Xiaoming. DSP Control For Motors - TI DSP application[M]. The Beijing university of aeronautics \&astronautics press,2009:271-273

[6] E.PRASAD, B.SURESH,K.RAGHUVEER. Field Oriented Control of PMSM Using SVPWM Technique. Global Journal of Advanced Engineering Technologies, Vol1, Issue2-2012, ISSN: 2277-6370

[7] I.C. Stika, D.Matianu, L.Kreindler. Advanced Motor Control Development Platforms.ATEE.

[8] The MathWorks,Inc.Real-Time Workshop Embedded Coder 5 User’s Guide.2010

[9] TMS320x2833x,2823x Enhanced Pulse Width Modulator(ePWM) Module Reference Guide. TEXAS INSTRUMENTS 